\title{
Climatic analysis of the ventilation and thermal performance of a dome building with roof vent
}

\section{Zohreh Soleimani*}

Department of Architecture and Civil engineering, University of Bath, Bath, BA2 7AY, United Kingdom, *Corresponding author E-mail: zohreh_soleimani@yahoo.com

\section{John Kaiser Calautit}

Department of Architecture and Built Environment, University of Nottingham, Nottingham, NG7 2RD, United Kingdom, Email: john,calautit1@nottingham.ac.uk

\section{Katrina Calautit}

Department of Architecture and Built Environment, University of Nottingham, Nottingham, NG7 2RD, United Kingdom, Email: keyce_34@yahoo.com

\section{Ben Richard Hughes}

Department of Mechanical Engineering, University of Sheffield, Sheffield, S10 2TN, United Kingdom, Email: ben.hughes@sheffield.ac.uk

\section{Abstract}

The paper presents the climatic analysis of a naturally ventilated geodesic-type dome building situated in a hot climate. A comprehensive review of the literature was conducted to provide an overview of previous related research on dome-type roofs buildings. The two-floor geodesic dome building assessed in this study was based on a $3 \mathrm{v}$ Icosahedron type and had a roof vent for natural ventilation. The airflow and temperature distributions inside the building were simulated using Computational Fluid Dynamics (CFD) modelling with the standard k-epsilon turbulence model. The computational modelling was verified using sensitivity analysis and flux balance analysis. Validation was carried out by using a similar dome-shaped building model from the literature. The atmospheric boundary layer ( $A B L)$ flow was simulated in the computational domain for a more realistic predictions of wind conditions. The thermal comfort level was assessed using the Predicted Mean Vote (PMV) method. The results showed that integration of the roof vents was advantageous and could reduce the indoor temperature and also introduce fresh air particularly during winter. The results also revealed that natural ventilation using roof vents could not satisfy the thermal requirements during summer periods and potential cooling solutions that could be integrated into the system are discussed.

\section{Keywords}

Computational modelling; dome-shaped building; natural ventilation; thermal comfort

Number of words: 4,854

\section{List of notations}

$U \quad$ air velocity $(\mathrm{m} / \mathrm{s})$

$u \quad$ streamwise component of air velocity $(\mathrm{m} / \mathrm{s})$ 


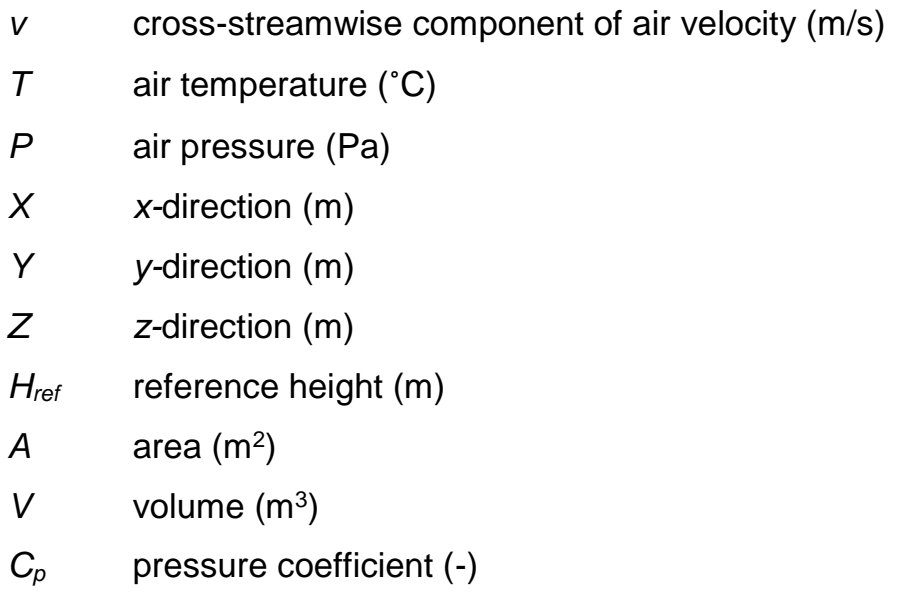

\section{Introduction}

The building sector is responsible for up to $40 \%$ of the annual global energy consumption and contributes up to $50 \%$ of the emissions (Calautit and Hughes, 2014; Jomehzadeh et al., 2017); hence reducing the energy use in this sector should be a priority for achieving the carbon emission reduction target. A large percentage of the building consumption comes from mechanical systems for heating, ventilation and air conditioning (HVAC). The air conditioning energy demand in the hot and arid cities such as Yazd can be as high as $80 \%$ during the summer season (Dabaieh et al., 2015). There has been a massive growth in the use of AC due to the increased demand for optimum indoor thermal comfort. Hence, lots of research has been focused on investigating passive strategies to reach the optimum combination of low energy and natural climatic control for buildings while active systems can become supplementary aids.

A passive cooling strategy is a building design method that focuses on controlling heat gain and dissipating heat to improve the indoor comfort with low energy systems or techniques (Hughes et al., 2012; Nejat et al., 2016b; O'Connor et al., 2017). A technique to minimise heat gains is by reducing the building surface area to volume ratio. For example, a building with a spherical shape will be more energy efficient than a typical cubic building with a similar volume in terms of heating and cooling requirements. According to (Passe and Battaglia, 2015), a dome-shaped building have $30 \%$ less surface area than a similar size box building which should result in lower heat transfer to and from its surroundings.

Dome roofs were used in traditional buildings in hot-arid regions such as the Middle East and the Mediterranean basin (see Figure 1) and played an important role in reducing roof heat gain and providing passive cooling in buildings. The initial reason for its use was the shortage of timber in the region (Bahadori and Haghighat, 1985). Several works have highlighted the capabilities of domed structures in keeping indoors cooler during the hot season and also lowering cooling loads. It reduces solar heat gains by lowering the exposed surface area to direct solar radiation (Marsh, 2006). Thermal comfort and energy efficiency can be improved by applying masonry thermal mass such as stone and adobe (Passe and Battaglia, 2015). 
Increased height of the interior allows rising warm air to be trapped at higher levels, which improves occupant comfort level in the lower zone (Fathy, 1986). A domed roof with an air vent at the top allows for the warm air to be exhausted (stack ventilation) and draw cool fresh air channelled into the space from small peripheral openings at lower levels (Levant, 2004). In addition to its thermal advantages, it also has other benefits such as structural advantages (selfsupporting arch and vault) and and availability of the construction materials (adobe, stone).

Figure1. Traditional buildings with dome roofs (Pixabay, 2017; Pexels, 2017)

In the late 1940s, the geodesic dome, which is a spherical form, comprised of a complex network of triangles or polygonal facets was developed by R. Buckminster Fuller. As the triangles network becomes more complex, the dome gets closer to the shape of a true sphere. Compared with masonry domes, where the stresses are distributed in arches, the geodesic dome distributes the stresses within the structure itself (Fathy, 1986). As compared a to flat roof building, a dome-shaped building provides larger interior space free from columns and also requires less building materials (Hogan, 2015). Figure 2 shows examples of modern geodesic domes.

Figure 2. Example of modern geodesic dome buildings (Pixabay, 2017)

\section{Literature Review}

This section provides an overview of previous works on the analysis of dome and curve type roofs/structures using different methods such as experimental, analytical and numerical modelling.

Bahadori and Haghighat (1985) conducted analytical modelling of the natural ventilation in buildings with dome roofs. Comparison with flat roofs showed that the dome roofs had higher air flow rate through the building. The work highlighted that the mean radiant temperature can be reduced substantially by dampening and evaporative cooling the internal surfaces, which can be accomplished by spraying water on the surfaces.

Tang et al. (2006) developed a finite element model to study the thermal performance of nonair-conditioned buildings with curved and flat roofs. The results highlighted that vault roof buildings had lower indoor air temperatures as compared to those with a flat roof, because such roofs dissipate more heat than a flat roof by convection and thermal radiation at night due to the enlarged curved surfaces. Moreover, a favourable thermal condition inside the vaulted roof building can be achieved with the half rim angle more than 50 degrees.

Lin et al. (2008) estimated the heating energy requirements of a dome-covered building using a transient three-dimensional thermal and airflow model. The proposed model was verified with 
simulation results from a CFD model developed using COMSOL Multiphysics and also with measurement data. Based on the results, the annual heating load of the dome building was $62.6 \%$ lower than the benchmark (uninsulated building).

Asfour and Gadi (2008) conducted CFD analysis of vaulted and domed roofs for improving natural ventilation performance. The study focused on optimising the airflow rate and the quality of internal airflow distribution. The effect of parameters including form of the building, area and porosity of the vault, and wind velocity and direction were assessed. The results showed that utilisation of vaulted roofs improved ventilation conditions in the upstream and central zones of the building, but not in the downstream zone. It was found that the dome was more effective in inducing air in the case of $0^{\circ}$ wind direction, and square building form while the vault has been found to be more effective in the case of $90^{\circ}$ wind direction.

Faghih and Bahadori (2009) conducted experimental analysis of the wind pressure coefficient over a dome-shaped roof using wind tunnel testing. The tests were conducted using a 1/10 scale model of the dome roof considering the presence of openings in the walls and a hole on top of the dome. The test focused on the dome CP under three different situations. The results showed that the maximum value of CP was observed at the lowest point of the dome facing the wind while the lowest $C_{P}$ was measured at the apex when the openings and the hole were all closed.

Lo and Kanda (2012) investigated the characteristics of wind pressure on the surface of dome roofs using wind tunnel testing. Two types of roof shapes and three heights of side walls were considered in the analysis. Positive wind pressure coefficients were measured in the windward area which was affected mostly by approaching wind. A thin shear boundary layer was formed along the roof surface and negative wind pressures were measured in the apex region and leeward region.

Khoshab and Dehghan (2014) employed CFD modelling to investigate the thermal behavior of the ventilated cavity with a domed roof under various operating condition. The geometry was based on a passively cooled reservoir. The dome roof prevents solar radiation heat gain in the summer and protects the water storage system from the hot outside environment. The work focused on studying the effect of Reynolds, Grashof numbers and inflow non-dimensional temperature on the airflow and thermal patterns.

Mahdavinejad et al. (2014) used analytical and CFD modelling to compare the ventilation and thermal performance of flat and domed roof in Tehran climatic conditions. Results showed that indoor temperature in the domed roof was $8^{\circ} \mathrm{C}$ lower as compared to the flat roof. Moreover, the geometry of the domed roof caused higher pressure difference between windward and leeward 
side which also resulted in improved natural airflow. Furthermore, the heat gain and loss were lower for the building with dome roof as compared with the flat roof.

Rahmatmand et al. (2014) conducted numerical and wind tunnel experimental investigation of the airflow and turbulence intensity distribution around a domed-roof building with windows and an aperture. The numerical model was used to simulate the flow field inside and outside the dome roof and calculate the discharge coefficient. The numerical results were validated using a 1:54 scale experimental model tested in a wind tunnel. The study highlighted the significance of using CFD modelling to analyse the airflow around this type of building which contains complex adjacent recirculation flows.

Based on the literature review conducted, there are many studies on the evaluation of the ventilation and thermal performance of buildings with dome roof or shape but studies on the geodesic dome type building or roof are limited. More attention has been given to the airflow pressure over domed roof and their wind driven ventilation performance. Many of the studies evaluated the performance of the dome-type during hot seasons and rarely in cold seasons. Most of the simulation studies did not include the impact of urban wind flows. No study assessed the thermal comfort levels in geodesic dome type building.

This study will investigate the airflow and thermal distribution in an isolated geodesic dome building with a roof vent located in a hot climate using CFD simulations based on a steady Reynolds-Averaged Navier-Stokes (RANS) model. The impact of the roof vent and overall building shape on the natural ventilation and thermal comfort performance will be assessed in different climatic scenarios. The work will also focus on the modelling of outdoor conditions by simulating a realistic urban wind flow. The boundary conditions will be specified according to Architectural Institute of Japan (AIJ) guidelines for CFD simulation of urban wind flows. Sensitivity analysis of the grid resolutions will be conducted to verify the CFD method. In order to validate the modelling, additional simulation of a similar domed-roof building will be carried out for comparison.

\section{Numerical Modelling}

ANSYS Fluent commercial software was used to perform 3D Reynolds-Averaged Navier-Stokes (RANS) simulations based on control volume technique and the Semi-Implicit Method for Pressure-Linked Equations (SIMPLE) coupling algorithm with the second-order upwind discretisation (Chung, 2002). The standard k-epsilon was used as the turbulence model. The use of the standard k-e model to assess natural ventilation flows in buildings has been found to be suitable (Calautit et al., 2013a; Calautit et al., 2013b; Hughes et al., 2012). The governing equations for the momentum, continuity, energy and species equations and its derivations are not included here but can be found in the ANSYS15 Fluent theory guide (ANSYS, 2015). 


\subsection{CAD modelling and domain generation}

Geodesic domes can be classified into six different forms; 1-Icosahedron, 2-Octahedron 3Cube, 4-Cuboctahedron, 5-Truncated Octahedron and 6-Rhombicuboctahedron. Icosahedron is the basic form for most geodesic domes, which is categorised into different types named by $\mathrm{v}$ suffix, which is the number of subdivisions of the original triangle in the icosahedron (Mueller, 2013). Figure 3 shows an example of an Icosahedron dome. More subdivision of the geodesic dome makes it smoother and more complex. In this study, a 3v Icosahedron dome building was generated using computer-aided design (CAD) modeller as displayed in Figure 4. The two-floor dome building had a total height of 9.06 metres, based floor area of $143 \mathrm{~m}^{2}$ and volume of $864 \mathrm{~m}^{3}$. The dome building design included a multi-directional roof vent for natural ventilation of the space.

Figure 3. Icosahedron dome (a) top (b) front (c) perspective view (Mueller, 2013)

In order to generate the computational domain for flow simulations (Figure 5), the CAD model was imported into ANSYS Geometry to create the fluid volume and boundaries. The fluid volume comprised of the exterior which represented the outdoor environment and the interior domain which represented the geodesic dome building. The exterior domain consisted of an inlet on one corner and pressure outlet on the other side to simulate the wind across the geodesic dome building.

Figure 4. 3D model of the 3v 5/9 Icosahedron dome building and its dimensions

\subsection{Grid method and verification}

The grid used for the CFD simulations was unstructured grid with patch independent algorithm which ensures refinement of the grid where essential, but maintains larger elements where possible, allowing for quicker calculation (ANSYS, 2015; Nasir et al., 2017) Figure 5b displays the grid generated on the surface of the dome. The computational model comprised of $4,674,895$ elements. The modelling was verified using grid sensitivity analysis and flux balance analysis.

Figure 5. Schematic diagram of (a) domain and (b) grid of dome surfaces

A grid-sensitivity analysis was performed based on two additional grids; a coarser grid with $2,910,143$ elements and a finer grid with $8,185,701$ elements. This was carried out by comparing the airflow velocity results of each grid simulation, measured from a vertical line drawn in the centre of the dome building. Based on the results, the average error between fine and medium mesh results for the velocity was $5.72 \%$, with the maximum error at $9 \%$ (measured at $3.8 \mathrm{~m}$ ) equivalent to $\pm 0.018 \mathrm{~m} / \mathrm{s}$. In order to have a balance between computational speed 
and accuracy, the medium mesh was employed in this study.

\subsection{Boundary condition settings}

Boundary conditions were set using the guidelines proposed by the Architectural Institute of Japan (AIJ) for practical applications of CFD modelling to urban wind environment around buildings (Tominaga, 2008; Nejat et al., 2016a; Aquino et al., 2017). The dome building was assumed to be located in the city of Yazd, located in the central part of Iran in $31^{\circ} \mathrm{N}$ latitude, $54^{\circ} \mathrm{E}$ longitude and $1230 \mathrm{~m}$ altitude. Its mean annual temperature is more than $22^{\circ} \mathrm{C}$ (Taghizadeh Mehrjardi et al., 2009; Hosseini et al., 2016) thus based on Köppen classification it has a hot desert climate (BWh) (Kottek et al., 2006). Figure 6 shows the average monthly temperature and typical vertical wind velocity profile (Mostafaeipour, 2010) in Yazd which were imposed at the inlet of the domain (see Figure 5a) to simulate various outdoor conditions. The outlet of the domain was set as zero static pressure. The sides and top of the domain were set as symmetry boundary condition, indicating zero normal velocity and zero gradients for all the variables at these boundaries (Sofotasiou et al., 2016). The standard wall functions were applied to the wall boundaries except for the ground, which had its wall functions adjusted for roughness. All surfaces were modelled as adiabatic except for the heat source. In order to simulate the heat gains (occupants, lighting and equipment), a constant heat flux of $25 \mathrm{~W} / \mathrm{m}^{2}$ (Autodesk, 2011) was set for the floor surfaces (upper and lower) of the building. The Boussinesq model was used for the simulation of the buoyancy-driven flows and equations and its derivations are not included here but can be found in the ANSYS15 Fluent theory guide (ANSYS, 2015).

Figure 6. (a) Average air temperatures (World Weather Online, 2015) and (b) estimated approach flow profile (Mostafaeipour, 2010).

\subsection{Assessing solution convergence}

The convergence of the iterative CFD analysis was assessed by monitoring the residual values, solution imbalance and quantities of interest. The default convergence criterion in FLUENT requires the residuals to decrease to $10^{-3}$ for all the equations except for energy for which the criterion is $10^{-6}$. However, this criterion does not apply to all type of simulations and integrated quantities (airflow velocity in different locations) were monitored instead and the iteration process was continued until there was no/minimal difference between iterations. Furthermore, the conservation of properties (mass flux balance) was also achieved. The mass flux balance was below the required value and all other equations respectively.

\subsection{Validation of modelling method}

A similar dome shape building model (Rahmatmand et al., 2014) was used for validating the current method. The justification for the selection of this particular model is the similarities in terms of the geometrical shape, inflow boundary conditions, type of grid and modelling procedure and also availability of wind tunnel results. Figure 7 a compares the results of the 
simulation in this study with the numerical and experimental results of the velocity component $u$ and $v$ obtained from the location $z / H_{r e f}=-0.163$ and a good agreement can be observed between the results. Figure $7 b$ compares the velocity profile from the location $z / H_{\text {ref }}=-0.155$ and a good agreement can be observed between the results although the current study model was more consistent with the experimental data.

Figure 7. Comparison between current model predictions and numerical/experimental data

(Rahmatmand et al., 2014) for velocity results at (a) $z / \mathrm{H}_{\text {ref }}=-0.163$ and (b) $z / \mathrm{H}_{\text {ref }}=-0.155$.

\section{Results and Discussion}

\subsection{Ventilation and thermal analysis}

In order to better analyse the effect of the geodesic dome geometry on the flow pattern around and inside the building, contours of the static pressure and velocity vector in the vertical center plane are shown in Figure 8. To evaluate the basic ventilation performance of the roof vent, wind direction was fixed at $0^{\circ}$ and other openings were assumed to be sealed off. As observed, the wind enters from the left velocity-inlet wall and moves toward the right pressure outlet wall. When the wind passed through the building, it induced a positive pressure on the windward side (maximum 1.5Pa), negative pressure on the leeward side $(-0.8 \mathrm{~Pa})$ and top of the roof vent (minimum of $-3 \mathrm{~Pa}$ ). This can be effectively utilised by locating windows in the lower levels to allow the air to flow through windward openings into the building to the low-pressure openings at the leeward face and roof vents. For this particular configuration (only roof vent ventilation), adequate air movement was still observed inside the space particularly in the upper floor. The internal pressure is mostly homogeneous on the upper and lower floor air static pressure at 1.6Pa. The lowest indoor pressure $(-2 \mathrm{~Pa})$ was measured for a small area at the centre of the recirculation zone in the upper floor. As observed from the vector diagram, the roof vent acted like an air curtain limiting the stale air or contaminants from exiting the indoor space. However, fresh outdoor air was still observed entering from the top right corner of the roof vent.

Figure 8. Contours of static pressure and velocity vectors $\left(U_{H 10 m}=3.0 \mathrm{~m} / \mathrm{s}\right)$.

To illustrate the flow field, velocity distribution contours as well as velocity streamlines in the vertical centre plane are plotted in Figure 9 . The velocity profile in front of the building was not affected significantly, and it follows the distribution of the Atmospheric Boundary Layer flow profile. As the wind passed through the building, the flow split and was diverted into several streams - one flow path rise over the building and two go around it. The fourth moved downward along the windward side, eventually met the ground and then moved back upstream forming a reverse flow. A complex flow structure occurred behind the building due to its specific shape, one large vortex was observed in the building's leeward side. As discussed previously, opening windows in the building on the windward and leeward side will force airflow through the building because of the pressure difference between the openings. Furthermore, air movement can also be generated in the building due to the natural tendency of warm air to rise (known as thermal 
buoyancy effect) and significant height of the dome. By placing openings in both the upper (roof vent) and lower levels of the geodesic dome, warm air is allowed to rise out of the upper part of the building and draw fresh and cooler air into the lower levels of the building. As observed in Figure 9, air circulation within the building was affected by the geodesic dome-shaped ceiling, height of inlet and outlet vents and the interior floor slab. The outdoor airflow was seen lifting up as it approached the geodesic dome building and accelerated near the top where the roof vents were located. The roof vents partially captured the airflow and redirected it to the leeward wall of the geodesic dome and to the floor forming a large recirculation flow in the upper floor area. With an outdoor wind velocity of $U_{H 10 m}=3.0 \mathrm{~m} / \mathrm{s}$, the maximum air speed near the ceiling of the upper floor reached $1.8 \mathrm{~m} / \mathrm{s}$ and reached the minimum of $0.05 \mathrm{~m} / \mathrm{s}$ in the lower floor and windward section of the upper floor. The ventilation rate was $7.71 / \mathrm{s}$ per $\mathrm{m}^{2}$.

Figure 9. Contours of velocity and streamlines $\left(\mathrm{U}_{\mathrm{H} 10 \mathrm{~m}}=3.0 \mathrm{~m} / \mathrm{s}\right)$.

Figure 10 displays a cross-sectional plot of the airflow of temperature distribution (in Celsius) inside the building. It was observed that the temperature inside the space was greatly varied, with lower temperature in the upper floor than the lower floor. Outdoor air at $14{ }^{\circ} \mathrm{C}$ flowed in the building though the roof vents and cooled down the interior of the space of the lower floor (average: $35.4^{\circ} \mathrm{C}$ ) and upper floor (average: $32.3^{\circ} \mathrm{C}$ ). Lowest temperature $\left(17^{\circ} \mathrm{C}\right.$ ) was observed close to the roof vents and highest temperature $\left(37^{\circ} \mathrm{C}\right)$ was observed close to the bottom right corner where there was low airflow movement. The temperature increased in the upper floor from the right corner $\left(17^{\circ} \mathrm{C}\right)$ towards the centre $\left(22^{\circ} \mathrm{C}\right)$. It was also observed that the roof vent did not effectively exhaust the warm air out of the space. As stated previously, the roof vent acted like an air curtain limiting the heat removal. Lower openings must be utilised to further cool down the lower floor and take advantage of the natural ventilation strategy.

Figure 10. Contours of temperature.

\subsection{Climatic analysis}

In order to study wind flow and thermal characteristics, 18 different points at $1.2 \mathrm{~m}$ and $4.2 \mathrm{~m}$ height were located inside the building for airflow velocity and temperature measurement. The annual variation of average airflow velocity in various points in the building is shown in Figure 11 and 12. As observed, the average velocity (point1-9) in both floors reached its maximum $(0.11 \mathrm{~m} / \mathrm{s})$ in July and the lowest average velocity $(0.048 \mathrm{~m} / \mathrm{s})$ was recorded in November and December. For the upper floor, the minimum average velocity was measured at point 3 $(0.05 \mathrm{~m} / \mathrm{s})$ and the maximum average velocity was measured at point $8(0.17 \mathrm{~m} / \mathrm{s})$. For the lower floor, the minimum average velocity was at point $5(0.05 \mathrm{~m} / \mathrm{s})$ and the highest average velocity was at point 9 (average $=0.12 \mathrm{~m} / \mathrm{s}$ ). Also in the lower floor, higher air speed was observed for the right corner points than the left points $(1,4$ and 7$)$ for this particular ventilation configuration and wind direction. On average, the airflow velocity in the upper floor was $28 \%$ higher than the lower floor. Overall, an irregular indoor airflow distribution was observed for both upper and lower floor 
which will have an effect on the thermal comfort levels of the occupant and will be discussed in the following sections. Table 1 summarises the calculated ventilation rates in $\mathrm{l} / \mathrm{s}$ per $\mathrm{m}^{2}$.

Figure 11. Annual predicted velocity for lower floor

Figure 12. Annual predicted velocity for upper floor

Table 1. Summary of the calculated ventilation rates $\left(1 / \mathrm{s}\right.$ per $\left.\mathrm{m}^{2}\right)$

Figures 13 and 14 compare the annual variation of the air temperature inside the naturally ventilated geodesic dome building. It was observed that the lower floor air temperature was higher than the upper floor $\left(3.14^{\circ} \mathrm{C}\right.$ higher on average) due to higher air movement and velocity in the upper floor. The difference in temperature between the floor levels was more significant during the winter (up to $4.3^{\circ} \mathrm{C}$ higher on average) when cool outdoor air enters the building to dissipate the internal heat gains. During the summer months the air temperature was more distributed uniformly in the lower floor compared with winter months. During the hottest months, maximum temperature was also observed for point 9 in the lower floor where the velocity is the highest as well (See Figure 11). A similar pattern was observed for the upper floor and this was because of the higher volume of hot outdoor airflow $\left(38-41^{\circ} \mathrm{C}\right)$ mixed with already heated internal air which will cause overheating during summer months.

Figure 13. Annual predicted temperature for lower floor

Figure 14. Annual predicted temperature for upper floor

\subsection{Thermal comfort analysis}

Thermal comfort expresses the occupants' satisfaction with a building's thermal environment. Several models or indices have been established to predict thermal sensation and comfort and the most common of these are the Predicted Mean Vote (PMV) and Physiologically Equivalent Temperature (PET) (ISO, 2005, Shahzad et al, 2017). The PMV predicts the average value of the votes of a group of occupants exposed to the similar thermal environment. It is expressed by the ASHRAE thermal sensation scale: +3 hot, +2 warm, +1 slightly warm, 0 neutral, -1 slightly cool, -2 cool and -3 cold (ASHRAE, 2013 radiant temperature, relative humidity, clothing and metabolic rate. In this study, the CFD temperature, velocity, humidity results were used to determine thermal comfort indices and assess acceptability of environmental conditions. Metabolic rate for the occupants and clothing insulation were assumed as standard values (see Table 1). Equations and derivations of the PMV are available in (ASHRAE, 2013). Figure 15 compares the PMV contours in the lower and upper floor when the outdoor temperature was at $14^{\circ} \mathrm{C}$ (winter month). As observed, the PMV values in the lower floor were all in the warm-cool range $(-0.83$ to 0.70$)$ while the upper floor were in the comfort-slightly cool range $(-0.85$ to 1.67). The combination of high air movement and colder temperature in the upper floor resulted in discomfort (avg. 42\% predicted percentage dissatisfied PPD) while the lower floor was in the 
comfort zone (5\% PPD). A significant difference in comfort level was observed between both floors which was due to the roof vents mainly ventilating the upper space. Therefore, a control strategy for the roof vent and other openings must be implemented to optimise the comfort levels in both floors. For each month, results are tabulated (Table 2) to show the environmental factors, clothing, metabolic rate and the thermal sensation PMV (predicted mean vote). As observed, during the summer months the average PMV were all above 3 (Hot) and clearly the roof vent natural ventilation would not satisfy the thermal requirements during these periods. This issue can be addressed by integrating other low energy cooling strategies such as evaporative cooling (Calautit, et al., 2013c), heat pipes (Chaudhry et al., 2016), phase change material (Akeiber et al., 2016) in to the system. Furthermore in areas with moderate to high relative humidity, passive desiccant dehumidification systems such as the technology in (O'Connor et al., 2016) can be employed.

Figure 15. Contours of thermal comfort level in (a) lower floor and (b) upper floor

Table 2. Summary of the predicted thermal comfort (PMV)

\section{Conclusions}

A ventilation and thermal performance study on a naturally ventilated dome shape residential building was presented. Computational Fluid Dynamics (CFD) simulations were conducted on the representative model of the building to observe the annual average air temperature distribution and air flow conditions inside the building which was naturally ventilated. The twofloor geodesic dome building was based on a $3 \mathrm{v}$ Icosahedron type and had a multi-directional roof vent for natural ventilation with the aim of offering indoor air temperature reductions and increased ventilation rates. The standard k-epsilon was used as the turbulence model. The indoor heat gain was simulated by settings a constant heat flux on the floor surfaces. The inlet wind speed and temperature were based on typical local conditions. For more realistic wind conditions, the atmospheric boundary layer $(\mathrm{ABL})$ flow profile was simulated. Grid sensitivity analysis and flux balance-analysis were utilised to verify the computational modelling. Validation was also carried out by using a similar dome shape building model from the literature. Overall, the numerical code was capable of accurately simulating the wind flow conditions around a domed-roof building and was therefore employed in this study. The results showed that using the roof vents was advantageous and could reduce the indoor temperature and also introduce fresh air particularly during winter periods. The dome shape roof vents had a significant impact on the internal conditions creating swirling flows in the upper floor, which also resulted in uneven ventilation and thermal distribution between upper and lower floor. On average, the airflow velocity in the upper floor was $28 \%$ higher than the lower floor. Overall, irregular indoor airflow distribution was observed for both upper and lower floor which had an effect on the thermal comfort levels of the occupants. Therefore, a control strategy for the roof vent must be implemented to to optimise the indoor velocity and temperature. Although the roof vent was capable of supplying fresh air into the building, it was observed that it did not effectively exhaust 
the warm air out of the space.The roof vent acted like an air curtain limiting the stale air or contaminants from exiting the indoor space. Lower openings must be utilised to address this and take advantage of the natural ventilation strategy. Furthermore, adding a divider in the roof vents to have inlet and outlet shafts could improve the ventilation strategy. The results also showed that natural ventilation using roof vent could not satisfy thermal requirements during hot summer periods and mechanical or evaporative cooling is required. To maximise the savings of active cooling and enhance the natural ventilation performance during the summer months, adequate amount of thermal mass with night cooling strategy could be one potential approach. It is also important to note that the limitation of this work is it did not consider the influence of nearby buildings and wind angles which are recommended for future research. Potential of integrating low energy cooling methods such as evaporative-cooling and PCMs should be investigated.

\section{Acknowledgements}

The authors would like to acknowledge the support of the University of Sheffield for providing the computational resource for this project.

\section{References}

Aquino Al, Calautit JK and Hughes BR (2017) Integration of aero-elastic belt into the built environment for low-energy wind harnessing: Current status and a case study. Energy Conversion and Management. http://dx.doi.org/10.1016/j.enconman.2017.03.030

Autodesk. Equipment and Lighting Loads. Available online: http://sustainabilityworkshop.autodesk.com/buildings/equipment-and-lighting-loads, accessed on 16 August 2016.

ANSYS Inc. PDF Documentation for Release 15.0. Available online: http://148.204.81.206/Ansys/readme.html, accessed on 16 August 2016.

Akeiber H, Nejat P, Majid MWahid Mazlan A, Jomehzadeh F, Famileh I, Calautit JK, Hughes BR and Ahmad Z (2016) A review on phase change material (PCM) for sustainable passive cooling in building envelopes. Renewable and Sustainable Energy Reviews 60:1470-1497.

Asfour O and Gadi M (2008) Using CFD to investigate ventilation characteristics of vaults as wind-inducing devices in buildings. Applied Energy 85:1126-1140

ASHRAE, ASHRAE Standard 55-2010: Thermal Environmental Conditions for Human Occupancy. Atlanta: American Society of Heating, Refrigerating and Air-Conditioning Engineers, 2010.

Bahadori MN and Haghighat F (1985) Passive cooling in hot arid regions in developing countries by employing domed roofs and reducing the temperature of internal surfaces. Building and Environment 20(2):103- 113.

Calautit JK, Hughes BR and Ghani SA (2013a) A Numerical Investigation into the Feasibility of Integrating Green Building Technologies into Row Houses in the Middle East. Architectural Sci Rev 56: 279-296.

Calautit JK, Hughes BR and Ghani SA (2013b) Numerical investigation of the integration of heat transfer devices into wind towers. Chem Eng T 34: 43-48.

Calautit JK, Chaudhry HN, Hughes BR and Ghani SA (2013c) Comparison between evaporative cooling and a heat pipe assisted thermal loop for a commercial wind tower in hot and dry climatic conditions. Applied Energy, 101: 740-755

Calautit JKS and Hughes BR (2014) Integration and Application of Passive Cooling Within a Wind Tower. HVAC\&R Research 20: 722-730.

Chaudhry HN, Calautit JK and Hughes BR (2017) Optimisation and analysis of a heat pipe assisted low-energy passive cooling system, Energy and Buildings, http://dx.doi.org/10.1016/j.enbuild.2017.02.002 
Chung TJ (2002) Computational Fluid Dynamics, Cambridge University Press; illustrated edition, ISBN-0521594162.

Dabaieh M, Wanas O, Hegazy MA and Johansson E (2015) Reducing cooling demands in a hot dry climate: A simulation study for non-insulated passive cool roof thermal performance in residential buildings. Energy and Buildings 89:142-152.

Faghih AK and Bahadori MN (2009) Experimental investigation of air flow over domed roofs. Iranian Journal of Science \& Technology. Transaction B Engineering 33: 207-216.

Fathy H (1986) Natural Energy and Vernacular Architecture: Principles and Examples with Reference to Hot Arid Climates. Chicago and London: The University of Chicago Press.

Geo-dome (2007) Getting a flat base on a 3 frequency dome. Available: http://geodome.co.uk/article.asp?uname=domefreq. Last accessed 2015.

Hogan MK (2015) 5 great reasons to build a geodesic dome home. Available: http://inhabitat.com/5-great-reasons-to-build-a-geodesic-dome-home/. Last accessed 23/11/2015.

Hosseini SH, Shokry E, Hosseini AJ, Ahmadi G and Calautit JK (2016) Evaluation of airflow and thermal comfort in buildings ventilated with wind catchers: Simulation of conditions in Yazd City, Iran. Energy for Sustainable Development 35:7-24

Hughes BR, Calautit JKS and Ghani SA (2012) The development of commercial wind towers for natural ventilation: A review. Applied Energy 92: 606-627.

ISO, ISO 7730: 2005. Ergonomics of the thermal environment - analytical determination and interpretation of thermal comfort using calculation of the PMV and PPD indices and local thermal comfort criteria

Jomehzadeh F, Nejat P, Calautit JK, Yusof M, Zaki S, Hughes BR, Afiq M and Yazid W (2017) A review on windcatcher for passive cooling and natural ventilation in buildings, Part 1: Indoor air quality and thermal comfort assessment, Renewable and Sustainable Energy Reviews 70: 736-756.

Kottek M, Grieser J,Beck C, Rudolf B and Rubel F (2006) World Map of the Köppen-Geiger climate classification updated. Meteorologische Zeitschrift, 15(3): 259-263.

Khoshab M and Dehghan A (2014) Numerical Simulation of Mixed Convection Airflow Under a Dome-Shaped Roof. Arabian Journal for Science and Engineering 39:1359-1374

Luomoconlavaligia (2014) Kenya,Un posto Straordinario. Available: http://www.luomoconlavaligia.it/kenya.html. Last accessed 12th Dec 2015.

Levant C (2004) Traditional Syrian Architecture. Handbook for the maintenance and rehabilitation of traditional Syrian architecture. France.

Lin $Y$ and Zmeureanu R (2008) Three-dimensional thermal and airflow (3D-TAF) model of a dome-covered house in Canada. Renewable Energy 33: 22-34.

Marsh AJ (2006) Domes and Solar Radiation. Available: http://naturalfrequency.com/articles/solardomes. Last accessed 2015.

Mahdavinejad MJ and Javanroodi K (2014) Efficient Roof Shapes through Wind Flow and Indoor Temperature, Case Studies: Flat Roofs and Domed Roofs. Armanshahr Architecture \& Urban Development 12: 55.

Mostafaeipour A (2010) Feasibility study of harnessing wind energy for turbine installation in province of Yazd in Iran. Renewable and Sustainable Energy Reviews 14: 93-111.

Mueller RK (2013) Geodesic Dome. Available: https://simplydifferently.org/Geodesic_Dome_Notes?page=2. Last accessed 2015.

Nasir DSNM, Hughes, BR and Calautit JKS (2017) A CFD analysis of several design parameters of a road pavement solar collector (RPSC) for urban application. Applied Energy 186: 436-449.

Naturalspacesdomes (2015) Domes Available: http://www.naturalspacesdomes.com/domes_sold.htm\#Kansas. Last accessed 2015.

Nejat P, Calautit JK, Majid M, Hughes BR and Jomehzadeh F (2016a) Anti-short-circuit device: A new solution for short-circuiting in windcatcher and improvement of natural ventilation performance. Building and Environment 105: 24-39.

Nejat P, Calautit JK, Majid M, Hughes BR, Zeynali I and Jomehzadeh F (2016b) Evaluation of a two-sided windcatcher integrated with wing wall (as a new design) and comparison with a conventional windcatcher, Energy and Buildings 126: 287-300.

O'Connor D, Calautit JKS and Hughes BR (2016) A novel design of a desiccant rotary wheel for passive ventilation applications. Applied Energy 179:99-109 
O'Connor D, Calautit JKS and Hughes BR (2017) A review of heat recovery technology for passive ventilation applications. Renewable and Sustainable Energy Reviews 54:14811493

Passe U and Battaglia F (2015) Designing Spaces for Natural Ventilation: An Architect's Guide. USA, Taylor\&Francis.

Pixabay. Available online: https://pixabay.com/en/turkey-istanbul-bosphorus-1405276/ (accessed on 12 Jan 2017).

Pexels. Available online: https://www.pexels.com/photo/view-of-temple-against-cloudy-sky326716/ (accessed on 12 Jan 2017).

Pixabay. Available online: https://pixabay.com/en/berlin-reichstag-the-german-volke-971799/ (accessed on 12 Jan 2017).

Pixabay. Available online: https://pixabay.com/en/switzerland-sky-clouds-cern-93275/ (accessed on 12 Jan 2017).

Rahmatmand, A.; Yaghoubi, M.; Rad, E.G.; Tavakol, M.M. 3D experimental and numerical analysis of wind flow around domed-roof buildings with open and closed apertures. Build. Simul. 2014, 7, 305-319.

Sofotasiou P, Calautit JK, Hughes BR and O'Connor D (2016) Towards an integrated computational method to determine internal spaces for optimum environmental conditions. Computers \& Fluids 127: 146-160

Shahzad S, Brennan J, Theodossopoulos D, Hughes BR and Calautit JK (2017) Energy and comfort in contemporary open plan and traditional personal offices. Applied Energy 185: 2, 1542-1555.

Taghizadeh Mehrjardi R, Mahmoodi S, Heidari A and Akbarzadeh A (2009) Micromorphological evidences of climatic change in Yazd region, Iran. Journal of Mountain Science, 6(2):162 172.

Tang R, Meir IA and Wu T (2006) Thermal performance of non air-conditioned buildings with vaulted roofs in comparison with flat roofs. Building and Environment 41(3):268-276.

Tominaga Y, Mochida A, Yoshie R, Kataoka H, Nozu T, Yoshikawa M and Shirasawa T (2008) AlJ guidelines for practical applications of CFD to pedestrian wind environment around buildings. Journal of Wind Engineering and Industrial Aerodynamics 96:1749-1761

World Weather Online (2015) Average High/Low Temperature for Yazd, Iran. Available: http://www.worldweatheronline.com/yazd-weather-averages/yazd/ir.aspx 